\title{
DEVELOPING IFC FOR INFRASTRUCTURE: A CASE STUDY OF THREE HIGHWAY ENTITIES
}

\author{
G. S. Floros ${ }^{* 1}$, G. Boyes ${ }^{1}$, D. Owens ${ }^{2}$ and C. Ellul ${ }^{1}$ \\ ${ }^{1}$ Dept. of Civil, Environmental \& Geomatic Engineering, UCL, Gower Street, London, WC1E 6BT, UK - \\ george.floros.17@ucl.ac.uk; gareth.boyes.13@ucl.ac.uk; c.ellul@ucl.ac.uk \\ ${ }^{2}$ Costain Plc., Vanwall Business Park, Maidenhead, Berkshire SL6 4UB, UK- davids.owens@ costain.com
}

KEY WORDS: Industry Foundation Classes (IFC), Asset Management, Infrastructure, Highway, Entities

\begin{abstract}
:
Modern cities pay particular attention to upscale their infrastructure systems in order to improve the every-day life of their citizens and lead the way towards a more sustainable environment. As part of this, they invest extensive funds in large infrastructure projects which are challenging to deliver as they require an e efficient communication among different professions, in order to share information efficiently throughout the lifecycle of the project, thus highlighting the importance of standardization to maintain consistency and integrity during data exchange. Building Information Modelling (BIM) aims to facilitate the above- mentioned requirements by describing the life-cycle of the project and Industry Foundation Classes (IFC) is the Standard for BIM that enables an efficient storage, management, exchange and visualization of information. However, there are two important challenges that need to be addressed: (i) IFC focuses particularly on buildings and provides limited support for infrastructure elements and (ii) the information exchange aims to describe mostly the construction phase; highlighting the lack of classes that refer to the operation and maintenance phase. Within this context, this paper proposes the extension of Industry Foundation Classes (IFC) for Asset Management in Infrastructure. A method is developed based on a case study of three highway entities: (i) retaining wall, (ii) gantry and (iii) bridge and a conceptual extension is presented. The results are further discussed and recommendations regarding future research fields are proposed.
\end{abstract}

\section{INTRODUCTION}

\subsection{Motivation}

The emerging development of the built environment to accommodate the demands in infrastructure of the modern cities requires a transition from traditional $2 \mathrm{D}$ paper-based plans to $3 \mathrm{D}$ digital models (Jeong \& Le, 2015). While the implementation of $3 \mathrm{D}$ models may often become costly in terms of resources and time, 2D models are not adequate to verify of the accuracy of the constructed project, while 3D models enable a thorough understanding of the relationships among the project's core elements and allow stakeholders to monitor and manage more efficiently the life-cycle of the construction or visualize the existing infrastructure and simulate future extensions and interactions with its surrounding area.

The above-mentioned examples underpin the importance of applying digital 3D models for engineering purposes. The divergent phases and involved stakeholders during the life- cycle of a project, highlight the issue of efficiently connecting the different domains and ultimately delivering the right piece of information to the right party at the right time. Exchanging data in such a complex environment results in challenges regarding data interoperability, management and sharing. There is a vast availability of software tools that generate Building Information Modelling (BIM) models to be implemented in various application fields. These tools differ from each other in terms of modelling techniques, data storage, model extension and userfriendliness. Common issues include the difficulties in accessing the files, the possibility of missing information when opened on a different viewer, but more importantly the option to enrich the model with data provided from different stakeholders that participate in the project (Zhou et al., 2017), highlighting the importance of exchanging information in a standardized format throughout the lifecycle of a project (Zhiliang et al., 2010).
While some research has been focused on interoperability within the design and construction phase (Amann, 2015; Kivits, 2013) there is less focus on interoperability between construction and operation - to underpin tasks such as Asset Management. Asset Management provides information regarding the value of an asset (Shah, 2017), while the increasingly stricter criteria in infrastructure regarding safety and efficiency under the pressure of constantly lowering the construction cost, has highlighted its implementation as a tool to obtain better results by utilizing fewer resources (Moon et al., 2009).

\subsection{IFC \& Standardization}

One approach to tackle these interoperability issues is standardization. Industry Foundation Classes (IFC) (buildingSMART, 2016) is the BIM Standard, aiming to bridge the gap between the professionals that operate in the Architecture-Engineering-Construction (AEC) domain.

IFC provides classes that primarily support the Building object with focus on its construction phase (Theiler, 2018; Marchant and Plume, 2017) while the incorporation of relevant information to infrastructure works is feasible by extending the desired entity (Lee et al., 2015). Infrastructure objects differ considerably from Buildings in terms of the elements they consist of, resulting in the expression via IFC with generalized classes. The lack of re-use of the expensive BIM data captured during the construction phase also means that extensive and costly data re-capture exercises are required to capture information for Asset Management when an infrastructure asset is handed over for operation. This generalization affects the infrastructure objects not only geometrically, but also semantically, rendering challenging the introduction of information related to Asset Management.

Therefore, the extension of IFC for Asset Management can be benefitted by the utilization of an existing Asset Information Management System. This system holds information that is 
relevant to the operational phase of a project's life-cycle and an integration with IFC that primarily supports the project's construction phase will assist in reducing the cost for data reacquisition and providing a single source of information for increased data integrity. Additionally, the $3^{\text {rd }}$ dimension is key as it facilitates the use of 3D asset models during the design, construction and maintenance phase of the built asset, forms the route for 4D simulations (Kivits, 2013) but also provides an extra incentive to capture the surrounding context of the asset, strengthening the integration with GIS Standards such as CityGML (OGC, 2012). Within this context, the purpose of this paper is to propose an IFC extension to support highways entities with attention on incorporating information related to Asset Management, based on a case study of three real-world highway entities: bridge, gantry and retaining wall.

\subsection{Research Question}

Hence, this paper sets the following research question:

"To which extent can an IFC extension suitable for Asset Management be developed from the Asset Data Management Manual for Infrastructure?"

The above-mentioned research question is split in the following sub-questions:

1. How suitable is the existing version of the ADMM for a transition to IFC format and to what extent is the information fit for asset management purposes?

2. How to embed the proposed extensions in IFC when: (i) there is an existing entity that partially describes the proposed one and (ii) the recommended entity is new?

\section{LITERATURE REVIEW}

\subsection{Industry Foundation Classes}

IFC is a standardized open data model based on the EXPRESS language as a part of the STandard for the Exchange of Product model data (STEP) standard for product data exchange (buildingSMART, 2016). IFC is used to describe, exchange, share and define how information should be stored throughout the building industry's life-cycle (El-Mekawy et al., 2012). In this paper, IFC4 Add2 version is utilized.

2.1.1. IFC Hierarchy \& Relationships: IFC is an objectoriented data model, which categorizes as a class every object or concept that is considered fundamental in the AEC industry, regardless if it contains geometric characteristics or not. Specifically, IFC distinguishes its entities based on whether they represent objects, semantic information or relationships (Theiler, 2018). Every object in IFC relates to its properties by utilizing different types of relationships. Thus, when creating a new entity, it is important to examine whether the existing relationship classes can facilitate the connection with the existing IFC schema. Within this context, IFC can be extended via three options: (i) introduce new entities, (ii) utilize proxy elements that serve the role of generic entities and (iii) extend the attributes of existing property sets (Zhiliang et al, 2010).

\subsection{IFC \& Highways Infrastructure}

IFC currently supports the "Building" object of a city, however lacks proper structure for the infrastructure objects (Amann, 2015). "IFC Alignment" is an extension of IFC developed from buildingSMART to address horizontal Infrastructure projects and is embedded into IFC 4x1 (buildingSMART, 2015; Niestroj et al., 2018; Amann et al., 2015). It formulates the basis upon complicated infrastructure works are to be built, by introducing the entities of "Horizontal and Vertical alignments". Ongoing work from buildingSMART also focuses on the development of IFC for Bridges and Roads. Within this context, Tanaka et al. (2016) propose an IFC schema suitable to support the inspection process of a bridge during its life-cycle. The "IFC Bridge" as proposed by Lebeque (2013) highlights the "objectified" structure of IFC, by connecting each entity with appropriate IFC relationships and utilizes the enumeration type of IFC (i.e. "Deck" is type of a Slab and not a separate class). Physical elements of the bridge are introduced via "IfcBridgeElement", while components that are less important from a structural point of view are stored as components.

"IFC Bridge - Fast Track Project" developed by the buildingSMART Infra Room (2018) presents a proposed extension for a bridge structure. The methodology highlights the decomposition of a bridge into components that include the geometry of the structure, its spatial characteristics and its semantic information. The developed schema proposes a new entity named "Facility" as a subtype of "IfcSpatialstructureElement", responsible to store the new "IfcBridge". The new schema also proposes the entity "FacilityPart", to describe the parts that form a bridge, by using enumeration values. Additional entities related to the bridge are also proposed in the existing entity "BuildingElements". The implementation is performed, either by introducing a new entity such as "Bearing", or by extending an existing one such as "Beam" with specific types of beam used in bridge construction. This paper examines the extension of the IFC schema by building mostly on existing entities to render the new additions more approachable to the academic and industry environment.

\subsection{IFC \& Asset Management}

The importance of having a data inventory of a project's assets (Shah, 2017) enables the implementation of asset management systems in IFC. The extensive utilization of BIM and 3D Modelling in the built environment enables the extension of IFC not only in infrastructure but also to incorporate information that are valuable in asset management. The current IFC schema does in fact support the storage of this information, however it does not fully address the asset management domain (Jackson, 2017). An IFC schema optimized for asset management should include information that describes the asset's performance and value, risk and warranty, energy requirements, and level of suitable use.

\section{DATA}

Key to extend IFC for highways infrastructure is the understanding of the objects that should be modelled. In this paper, the main source of information is the Asset Data Management Manual (ADMM), which is used as an Asset Management Information System for highway operation within "Highways England" (Highways England Asset Information Group, 2018) by specifying definitions, rules and requirements to ensure an efficient management of the project's assets. Also, to illustrate graphically the proposed IFC extensions, 3D models of a road gantry and a bridge are provided by the industry partner. The ADMM consists of two core components:

(i) ADMM Data Principles \& Core Requirements: a set of PDF reports, that describe the recommended approach in terms of rules, structure and data requirements. 


\begin{tabular}{|c|c|c|c|c|c|c|}
\hline Class & -7 Subclass & - Item_Name & $\nabla$ Item_code & Asset_Data_Category & Record_type & $-\pi$ \\
\hline Structures & Bridge and Large Culvert & BLC - BRIDGE \& LARGE CULVERT & BRBR & Inventory & Attribute & \\
\hline Structures & Bridge and Large Culvert & BLC - BRIDGE \& LARGE CULVERT & BRBR & Inventory & Attribute & \\
\hline Structures & Bridge and Large Culvert & BLC - BRIDGE \& LARGE CULVERT & BRBR & Inventory & Attribute & \\
\hline Structures & Bridge and Large Culvert & BLC - BRIDGE \& LARGE CULVERT & BRBR & Inventory & Attribute & \\
\hline Structures & Bridge and Large Culvert & BLC - BRIDGE \& LARGE CULVERT & BRBR & Inventory & Attribute & \\
\hline Structures & Bridge and Large Culvert & BLC - BRIDGE \& LARGE CULVERT & BRBR & Inventory & Attribute & \\
\hline Structures & Bridge and Large Culvert & BLC - BRIDGE \& LARGE CULVERT & BRBR & Inventory & Attribute & \\
\hline Structures & Bridge and Large Culvert & BLC - BRIDGE \& LARGE CULVERT & BRBR & Inventory & Attribute & \\
\hline Structures & Bridge and Large Culvert & BLC - BRIDGE \& LARGE CULVERT & BRBR & Inventory & Attribute & \\
\hline Structures & Bridge and Large Culvert & BLC - BRIDGE \& LARGE CULVERT & BRBR & Inventory & Attribute & \\
\hline Structures & Sign \& Signal Gantries & SSG - SIGN_GANTRY & GYGY & Inventory & Attribute & \\
\hline Structures & Sign \& Signal Gantries & SSG - SIGN_GANTRY & GYGY & Inventory & Attribute & \\
\hline Structures & Sign \& Signal Gantries & SSG -SIGN_GANTRY & GYGY & Inventory & Attribute & \\
\hline Structures & Sign \& Signal Gantries & SSG -SIGN_GANTRY & GYGY & Inventory & Attribute & \\
\hline Structures & Sign \& Signal Gantries & SSG - SIGN_GANTRY & GYGY & Inventory & Attribute & \\
\hline Structures & Sign \& Signal Gantries & SSG - SIGN_GANTRY & GYGY & Inventory & Attribute & \\
\hline Structures & Sign \& Signal Gantries & SSG - SIGN_GANTRY & GYGY & Inventory & Attribute & \\
\hline Structures & Sign \& Signal Gantries & SSG - SIGN_GANTRY & GYGY & Inventory & Attribute & \\
\hline Structures & Sign \& Signal Gantries & SSG - SIGN_GANTRY & GYGY & Inventory & Attribute & \\
\hline
\end{tabular}

Figure 1: Example of the ADMM Data Dictionary Structure \& Hierarchy

(ii) ADMM Data Dictionary: a Microsoft Excel spreadsheet that stores this type of information and facilitates a transition from verbally describing the objects and their relationships to a more structured representation (fig.1).

\subsection{Challenges}

The existing version of the ADMM forms a good starting point to gain an understanding of the different elements comprising each object and the type of information that is important for asset management. However, it is a product developed by merging numerous asset management systems of different dates that cannot cross-refer to each other, creating data integrity issues when trying to transition in IFC ${ }^{\mathbf{1}}$. The challenges are summarized below in table 1 :

\begin{tabular}{|l|l|}
\hline Issue & Description \\
\hline Inconsistency & $\begin{array}{l}\text { The inconsistent presentation of } \\
\text { objects and their elements in terms } \\
\text { of naming, prefixes and attribute } \\
\text { definition. }\end{array}$ \\
\hline $\begin{array}{l}\text { Duplicated } \\
\text { Information }\end{array}$ & $\begin{array}{l}\text { The element that possesses } \\
\text { attributes that essentially describe } \\
\text { or contain similar type of } \\
\text { information. }\end{array}$ \\
\hline Rules \& Constraints & $\begin{array}{l}\text { The elements that appear in an } \\
\text { infrastructure object (i.e. retaining } \\
\text { wall) but are not directly related } \\
\text { with it (i.e. carriageway } \\
\text { surfacing). }\end{array}$ \\
\hline Relationships & $\begin{array}{l}\text { The cardinality and multiplicity of } \\
\text { the relationships that connect the } \\
\text { elements with each other }\end{array}$ \\
\hline $\begin{array}{l}\text { Fragmented } \\
\text { Information }\end{array}$ & $\begin{array}{l}\text { Information such as the type of a } \\
\text { joint or values of an attribute are } \\
\text { verbally described as text }\end{array}$ \\
\hline
\end{tabular}

Table 1: Categories of data integrity issues in ADMM

1. This statement derives from discussions with representatives of Costain Plc.

\section{METHOD}

The developed method consists of three (3) phases: firstly, the conceptual mapping of the ADMM with the form of Unified Modeling Language (UML) diagrams is performed. This is followed by the generation of the final UML diagrams according to selected criteria and highway asset management requirements. Finally, the proposed UML diagrams are converted to EXPRESS-G diagrams in order to align with IFC's structure.

\subsection{Phase 1: ADMM to UML}

The ADMM is composed of several Microsoft Excel Spreadsheets that render its management and interpretation challenging, as described in Section 3. Therefore, a conversion to UML schematic diagrams was undertaken to facilitate a clearer understanding of the main entities, their attributes and relationships as well as the limitations compared to the structure of information required to extend IFC. Three types of infrastructure were selected as exemplars, based on industry partner requirements: (i) a retaining wall, (ii) a road gantry and (iii) a bridge. The UML definition of the entities with attributes and relationships is performed based on the information provided by the ADMM and is carried out manually.

\subsection{Phase 2: UML to IFC Structure}

The generated UMLs do not facilitate a smooth transition to IFC due to the unstructured and inconsistent storage of information, issues that Phase 2 aims to address. Thus, data manipulation is performed based on the following criteria, which are based on the IFC extension principles described in sub-section 2.1.1:

1. Fit for purpose: This criterion aims to create an intermediate structure based on ADMM to facilitate the transformation from IFC to ADMM, and also overcome some of the issues with ADMM as presented by Highways England, by manipulating the existing entities and attributes. Simultaneously, it enables a smoother extension of IFC, since the proposed entities are generalized and can be more efficiently incorporated in the existing IFC Schema.

Criterion nr. 1 is set to address the issue of the ADMM being a product of multiple merges of different asset management systems and therefore facing data duplication challenges. The 
goal is to introduce entities that are fit for purpose, as demonstrated by previous methods described in section 2.3 .

2. System Optimization: This criterion aims to tackle the inconsistency of the entities, attributes and relationships, forming UML that diagrams are more accurate in terms of the elements' structure, consistent in creating suitable names for the entities and the attributes and more clearly defined relationships based on the IFC specification.

Criterion nr. 2 is set to address the issue of introducing the least amount of entities or property sets when proposing an IFC extension, as described in section 2.2.

3. Expert's review: This criterion enables the implementation of feedback provided by the industry partner which supports the current paper.

Lastly, the proposed changes are reviewed by professional experts in the field, to further improve the proposed method.

\subsection{Phase 3: Generation of the proposed IFC Extension}

The final step of the proposed method is to embed the cleared UMLs in the IFC schema. Thus, it is important to cross-reference the proposed entities, relationships and attributes with the existing structure of IFC to highlight which information is unique or is already being described by the IFC. The process is split in three sections for each infrastructure object, focusing on the spatial aspect, the geometry/physical elements as well as the properties and attributes.

\section{CASE STUDY}

\subsection{Phase 1: ADMM to UML}

For each infrastructure object the corresponding entities are created based on the ADMM Data Dictionary. These entities refer hierarchically to the elements that form the main infrastructure object, highlighting a supertype-subtype relationship. For instance, a retaining wall is formed by panels which are further formed by movement and expansion joints. Subsequently, these entities are enriched with mandatory or optional attributes that derive from the respective ADMM columns. Fig. 3 presents the UML for the Retaining Wall. Similar diagrams have been created for the Bridge and the Gantry.

\subsection{Phase 2: UML towards IFC Structure}

The data cleaning and preparation of the UMLs to fit IFC Structure is performed based on the criteria described in Section 4. The task focuses on altering the existing ADMM entities, but also on introducing properties that are essential in asset management.

5.2.1 Attributes: To utilize an object for asset management purposes, it is essential that this object is accompanied by specific information attributes (Jackson, 2017, pp. 30-32). A comparison between attributes from the ADMM with the existing properties in IFC is performed as shown in table 2.

5.2.2 Entities: Table 3 presents a part of the implemented changes for the infrastructure entity: Bridge in Phase 2, which is the most complicated one in terms of elements, attributes and relationships. The method described in Chapter 4 is applied respectively for the Retaining Wall and Road Gantry entities.

\begin{tabular}{|l|c|}
\hline Attributes & Exist in IFC \\
\hline Date of Information & $\checkmark$ \\
\hline Suitability of Information & X \\
\hline Function & $\checkmark$ \\
\hline System Optimization Performance & X \\
\hline Structure Material & $\checkmark$ \\
\hline Energy Requirements & X \\
\hline Manufacturer & $\checkmark$ \\
\hline Installation Date & $\checkmark$ \\
\hline Inspection Frequency & $\checkmark$ \\
\hline Condition & $\checkmark$ \\
\hline Criticality & $\checkmark$ \\
\hline Risk & $\checkmark$ \\
\hline
\end{tabular}

Table 2: Comparison of Asset Management properties with existing property sets in IFC

\subsection{Phase 3: Generation of the proposed IFC Extension}

The last stage is the transition from UMLs to EXPRESS-G.

5.3.1 Spatial Structure: The "IfcSpatialStructureElement" currently consists of four entities. Therefore, the objects are defined spatially as supertypes in order to be connected with their sub-elements.

\section{IfcSpace}

The enumeration types: "GantrySpan" and "BridgeSpan" are recommended to enrich the existing "IfcSpace" predefined type (fig. 2). In this paper, "BridgeSpan" and "GantrySpan" is calculated as the space between two supports or beams. Their property set includes information regarding the "Name", "Connection Type" and "Width".
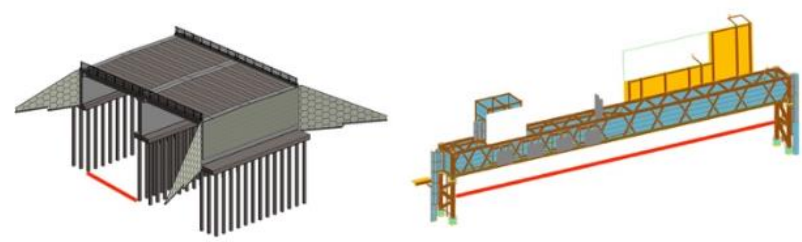

Figure 2: "BridgeSpan" and "GantrySpan" definition in red line

\section{IfcInfrastructure}

The entity "IfcInfrastructure" is proposed at the same hierarchical level as IfcBuilding, IfcBuildingStorey, IfcSpace and IfcSite. The main considerations in creating the above- mentioned class are: (i) a more organized structure, instead of placing objects such as bridge and roads separately and (ii) the possibility of extending the entity with different types of infrastructure generating a unified system (i.e. tunnels, highways).

\section{IfcBridge \& IfcTransportationNetwork}

The proposed extension follows the structure of IfcBuilding. Concretely, "IfcBridge" is a spatial entity, formed by physical elements and their properties. The connection is feasible utilizing the "IfcRelContainsInSpatialStructure" entity. 


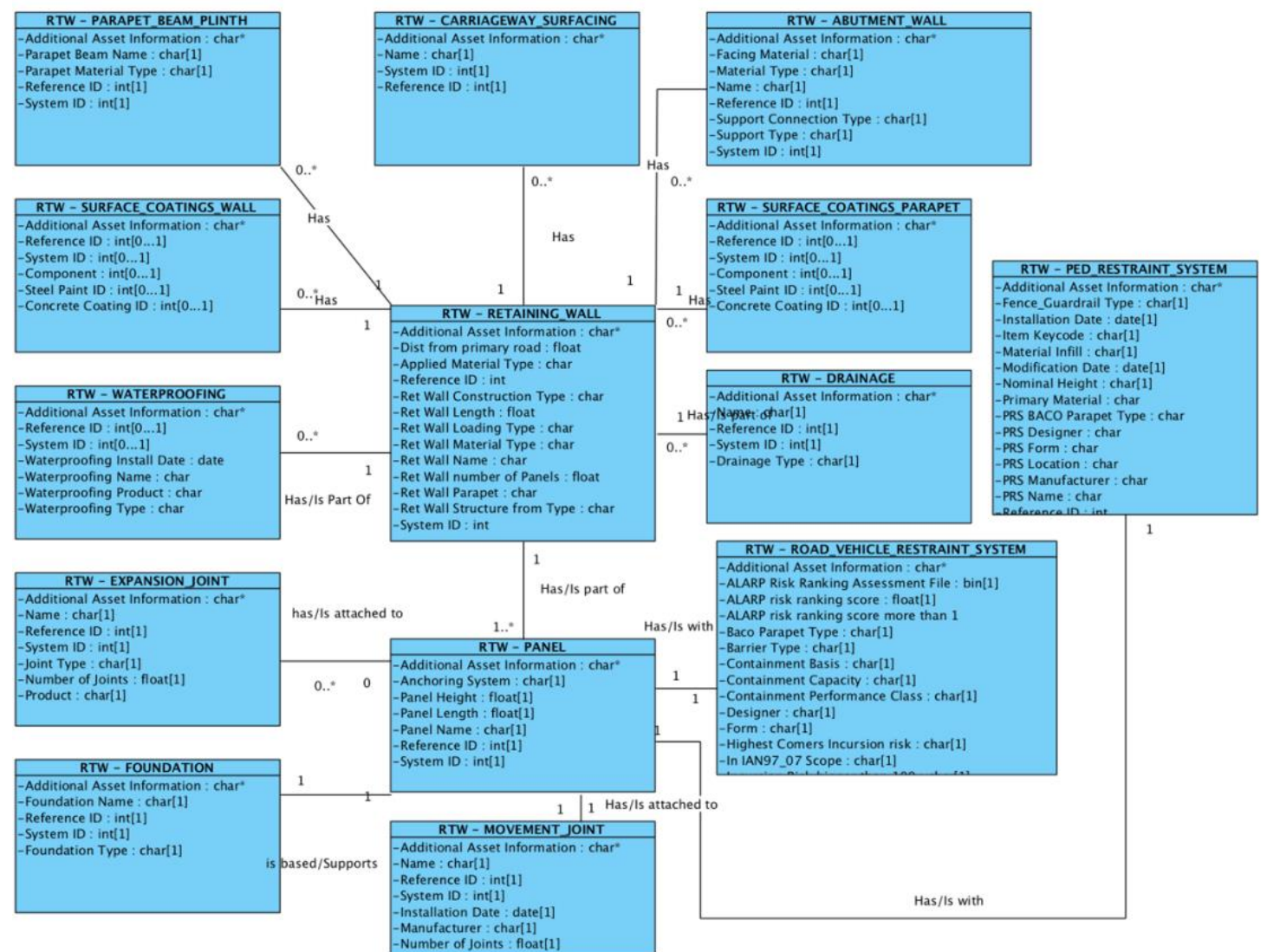

Figure 3: UML Diagram for the Retaining Wall

\begin{tabular}{|l|c|l|l|}
\hline \multicolumn{5}{|c|}{ Bridge } \\
\hline Object Type & Criterion & Implemented Change & Reasoning \\
\hline Approach Embankment & $1 \& 3$ & $\begin{array}{l}\text { The entity is replaced as an attribute } \\
\text { in "Deck" }\end{array}$ & $\begin{array}{l}\text { It is sufficient to store this type of information as } \\
\text { an attribute }\end{array}$ \\
\hline Apron & 2 & $\begin{array}{l}\text { The entity is replaced a material } \\
\text { attribute in "BridgePier" }\end{array}$ & $\begin{array}{l}\text { The entity is sufficient to exist as an attribute for } \\
\text { asset management purposes }\end{array}$ \\
\hline Bearing Shelf Plinth & $2 \& 3$ & $\begin{array}{l}\text { The entity is replaced as an attribute } \\
\text { in the "Bearing" }\end{array}$ & $\begin{array}{l}\text { The entity is sufficient to exist as an attribute for } \\
\text { asset management purposes }\end{array}$ \\
\hline Cable Anch Box & 2 & $\begin{array}{l}\text { The entity is related only with } \\
\text { "Pylon" and not with "Deck }\end{array}$ & $\begin{array}{l}\text { "Pylon" is modified to be a critical component of } \\
\text { the bridge }\end{array}$ \\
\hline $\begin{array}{l}\text { Cable Hangar \& Cable } \\
\text { System }\end{array}$ & $1 \& 2$ & $\begin{array}{l}\text { Both entities are replaced as } \\
\text { attribute "Type" in "Cable" }\end{array}$ & $\begin{array}{l}\text { The entities are secondary cables; therefore, they } \\
\text { are already expressed by "Cable" }\end{array}$ \\
\hline Carriageway Surfacing & 3 & $\begin{array}{l}\text { The entity is removed and added as } \\
\text { an attribute in the "Deck" }\end{array}$ & $\begin{array}{l}\text { Applying the same mindset for every material, it } \\
\text { is sufficient to be described as an attribute for } \\
\text { asset management purposes }\end{array}$ \\
\hline Cladding & 3 & $\begin{array}{l}\text { The entity is removed and } \\
\text { introduced as an attribute in the } \\
\text { "Deck" }\end{array}$ & $\begin{array}{l}\text { "Cladding" essentially refers to a surface } \\
\text { protective material, thus from an asset } \\
\text { management perspective, it is sufficient to be } \\
\text { included as an attribute }\end{array}$ \\
\hline Drainage & 1 & $\begin{array}{l}\text { The entity is removed and } \\
\text { introduced as an optional attribute } \\
\text { in "Retaining Wall" and } \\
\text { "BridgePier" }\end{array}$ & $\begin{array}{l}\text { The entity is part of a larger infrastructure system; } \\
\text { therefore, it is outside the scope of this paper }\end{array}$ \\
\hline Foundation & $1 \& 2$ & $\begin{array}{l}\text { The entity is removed and added as } \\
\text { an attribute in "Retaining Wall" }\end{array}$ & $\begin{array}{l}\text { None entity is removed } \\
\text { Theording to the ADMM, the entity is related } \\
\text { with the "Retaining Wall" }\end{array}$ \\
\hline Headwall & 3 tab & 1 & $\begin{array}{l}\text { The entity can be described by the attributes of } \\
\text { the "Retaining Wall" }\end{array}$ \\
\hline
\end{tabular}

Table 3: Criteria Implementation in Phase 2 for selected types of the Bridge 
On the other hand, "IfcTransportationNetwork" is fit for objects that compose a transportation network, such as roads, traffic elements and pavements. The paper is is focused on road gantries, therefore the entity "IfcRoadGantry" is proposed. However, similarly to IfcBridge", it is formed from physical elements and their attributes, utilizing the "IfcRelContainsInSpatialStructure" entity.

5.3.2 Physical Elements: The Retaining Wall is described as an enumeration type (ET) of the existing supertype "IfcWall", since it is a specific wall type. Additionally, the Panel which forms the wall is described similarly as an enumeration type by the "IfcWall", while the "IfcJoint" is introduced as a new entity. The "RelAggregates" facilitates the connection of the joints with the "IfcBuildingElement".

Regarding the Road Gantry, the "Bearing" and "Bracing" are described as new subtypes of the supertype "IfcBuildingElement". On the other hand, "GantryColumn" and "GantryBeam", "SignGantry", "SignSupport" and "Sign" are described as enumeration types of the existing "IfcBeam", "IfcColumn" and "IfcPlate" entities.

Regarding the Bridge, the entities "Deck", "BridgePier" and "Beam" are described from the existing IFC schema. Therefore, it is proposed to be added as enumeration types of the supertypes "IfcSlab", IfcColumn" and "IfcBeam". On the other hand, "BridgePylon", "Foundation", "Bearing", "Bracing", "BridgeCable" and "BridgeCableBox" are proposed as new entities.

\section{RESULTS}

Fig. 4 (up) demonstrates the "IFCSpatialElement" extension in EXPRESS-G. The proposed classes are highlighted in green against the existing IFC Structure which is presented in white font. The "IfcSpatialStructureElement" is extended with "IfcInfrastructure" that consists of "IfcBridge" and "Ifc TransportationNetwork" alongside their respective property sets. Regarding the spatial aspect of IFC for infrastructure, a general spatial entity ("Infrastructure") is introduced that is decomposed in respective infrastructure elements, such as bridges, highways and gantries, aiming to generate an extension that addresses the infrastructure objects as a system and not on an isolated basis.

Fig. 4 (down) demonstrates the "IfcElement" extension for the Bridge. "IfcBridge" is physically formed by "Deck"; an enumeration type of "IfcSlab" and new entities such as "Bracing" and "Bearing" are introduced as new classes. Property sets are assigned following the naming convention of existing "IfcPropertySets" for buildings. In terms of geometry, the extension is performed by proposing either new entities or new types of entities that represent geometric objects. Concretely, existing entities (i.e. slab) that partially describe a recommended entity (i.e. bridge deck) are enriched using IFC enumeration types. On the other hand, if the proposed entity is not currently covered by the existing IFC schema, then a new is introduced.

\section{DISCUSSION}

This paper proposes a method to develop an IFC extension for three highway infrastructure entities: a retaining wall, a road gantry and a bridge with emphasis on addressing asset management requirements. An IFC extension can be generated based on the content of the ADMM, however challenges occur regarding its original structure and compatibility with IFC format, as well as the fragmented description and linking of elements with each other. Three types of criteria are implemented to address data management challenges and move to EXPRESS$\mathrm{G}$ format. The advantages of the method focus on addressing the infrastructure as a system and not as separate unrelated entities, proposing the least amount of new entities in order to render the schema friendly to understand and process and lastly, the original attribute information of the ADMM is preserved in order to be further improved in the future. On the other hand, the main weakness of the method is related with the implementation of a conceptual model, since it is not tested in real-world data, but also with the fact that such a task can be further improved by sharing it with experts and professionals in order to constantly implement their feedback.

\subsection{Suitability of ADMM for IFC}

"How suitable is the existing version of the ADMM for a transition to IFC format and to what extent is the information fit for asset management purposes?"

The transition from the existing ADMM to an IFC extension is not straight- forward. The main reason is the fragmented nature of information stored in ADMM due to the fact that the current version is a merged product of different asset management systems. The key issues as identified in this paper are: data duplication, inconsistency and redundancy as well as abstract relationships and hierarchy. On the other hand, the ADMM is a valuable source of data to form a basis of how the infrastructure objects are structured and related with each other. The existing attributes assist in identifying the type of information that the infrastructure elements possess and facilitate a categorization in order to create generic or asset-management focused property sets in the developed method. Three types of criteria are implemented; however, it is important to investigate potential level of bias when evaluating the proposed extension.

While ADMM is designed and used for asset management there are specific requirements (Jackson, 2017), that are not explicitly met by the existing version. The geometric aspect of the infrastructure objects is adequately described, however complete semantic information relevant to asset management is not provided by the ADMM. For instance, the infrastructure objects omit important semantic information such as the energy requirements, the suitability of information associated with the object, the performance of the system, warranty and risk assessment among others. There is however, asset information that is covered by the ADMM, such as the manufacturer, date information and material type but the attributes are not associated with every object on a consistent basis. For instance, a retaining wall may contain information about the manufacturer compared to a bridge pier that may not include this type of attribute, raising the case of identifying whether it is important to hold a specifically designed asset management property sets to every object or not. So, on one hand it is necessary to build upon the existing information of ADMM, but is also essential to source external information, either from existing literature or from industry professionals in order to optimize the extension for asset management purposes. 


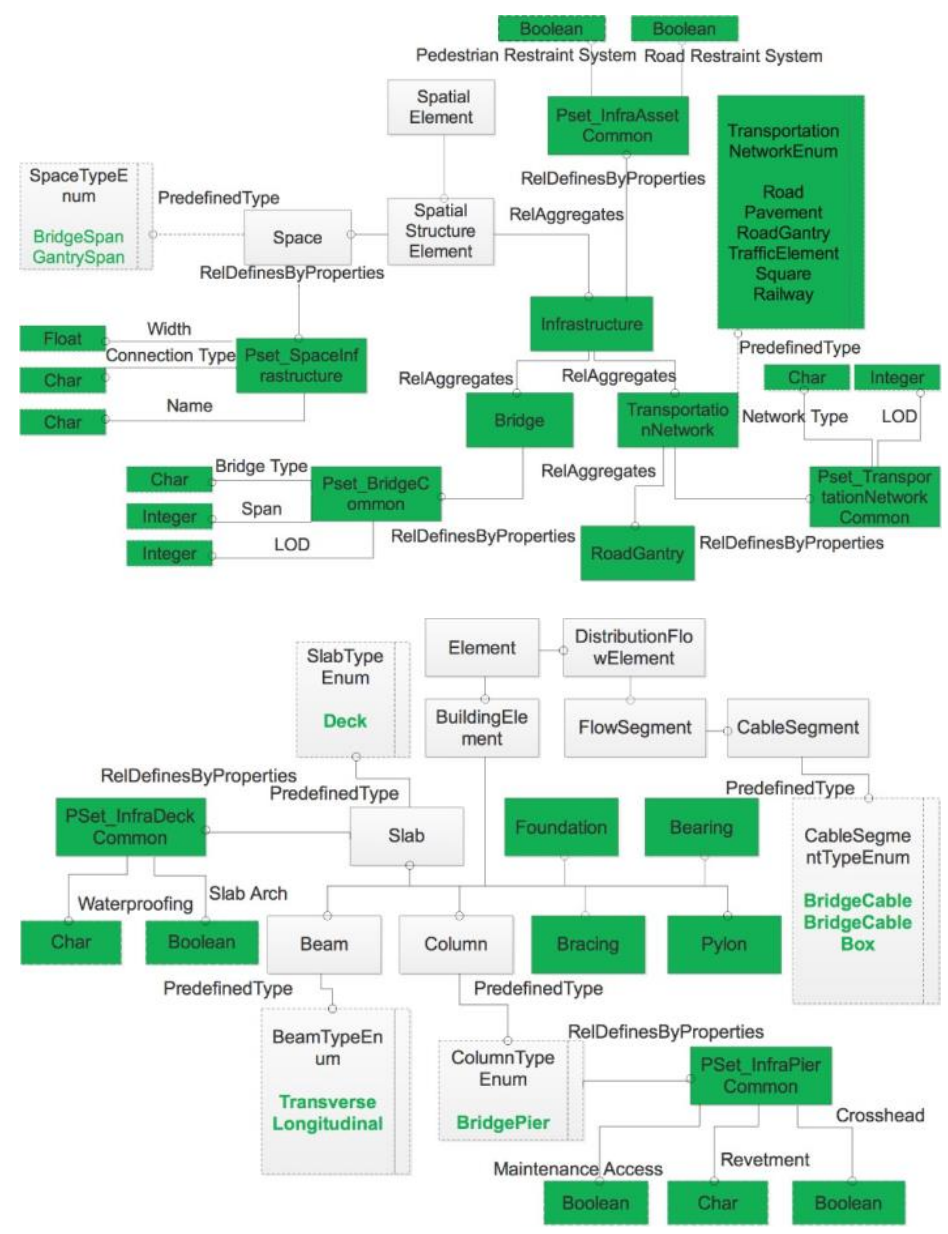

Figure 4: Proposed "IfcSpatialElement" extension (up) and "IfcElement" extension for Bridge (down)

\subsection{Extending IFC}

"How to embed the proposed extensions in IFC when: (i) there is an existing entity that partially describes the proposed one and (ii) the recommended entity is new?"

The developed extension is presented in EXPRESS-G since it is the native format of the IFC. Based on the process described above, it is suggested that a generation of a new schema should consider the following parameters: firstly, the goal is to propose an extension that adds the least amount of new entities in the existing IFC schema in order to make the extensions immediately available and understandable to the interested parties. Secondly, an IFC extension should aim to address infrastructure objects as a system and not as separate entities. Within this context, the method examines the spatial, geometric and semantic aspect of the extension separately. Furthermore, with regards to attributes and property sets, the results indicate that an adequate number of asset attributes as proposed by Jackson (2017) are already covered in the existing IFC schema. So, the new attributes are embedded as property sets designed for infrastructure and asset management in the general infrastructure object (i.e. retaining wall, bridge and road gantry) and not on the elements that form these objects. While it is possible to attach these properties to the sub elements, in this paper the aim is to develop a schema that can operate as a generalized system for all infrastructure objects. To elaborate further, the infrastructure object contains the general information that is important from an asset management point of view, to create a more consistent and "strict" schema, by utilizing supertype-subtype relationships and avoiding the introduction of many property sets in different elements. However, when it comes to the elements that form the infrastructure objects, the proposed property sets include the information as derived by the $2^{\text {nd }}$ phase of the method. More specifically, unique property sets are assigned to every element containing the attributes that derive from the merging and alterations of the original UML diagrams. For instance, the "BridgePier" is enriched with a property set that contains information about the "Maintenance Access", the "Revetment Type" and the "Crosshead", all referring to entities that have been merged and introduced as attributes during the $2^{\text {nd }}$ phase. This way, the method considers all the entities and attributes of the ADMM, simplifies the proposed extension and lowers the risk of losing valuable information by embedding it as property sets.

This paper proposes the following:

i. The ADMM should be re-organized with attention in defining more clearly relationships, attributes, rules and constraints between the different elements.

ii. Besides the re-structure of the ADMM, it is important to redefine or incorporate the complete asset information that is essential to the asset managers.

iii. The developed method could be further improved by implementing additional criteria specified by the collaboration among additional domains.

iv. $\quad$ Future extensions of IFC for could aim to address infrastructure as a system that is further decomposed in separate objects. 


\section{CONCLUSIONS \& FUTURE RESEARCH WORK}

The purpose of this paper is to introduce an extension for IFC for infrastructure. Large infrastructure projects, such as HS2 or Crossrail in the United Kingdom require the implementation of IFC, as the teams of different professionals (i.e. CAD \& BIM, GIS, Utilities, Asset Managers) create and manage different 3D models, but eventually the information needs to be shared amongst them and IFC is an option to tackle data interoperability. At the moment, this is partially feasible since the infrastructure objects are based on the Building entity, highlighting the necessity to develop separate entities for infrastructure. Furthermore, projects of such high-costs need to maintain an asset dictionary from the early stages of design. As IFC is used to exchange information, the implementation of asset management properties can facilitate a transition from document-based software to a combination of visual representation alongside the information that accompany every asset. Lastly, by proposing classes for infrastructure, this paper forms a basis upon integration with GIS Standards such as CityGML can be investigated and examine the level of information transferred between the BIM and GIS Standards.

Regarding future work, it is important to clarify and pinpoint the requirements that each domain sets, especially if the BIM-GIS integration is to be addressed. A comparison with infrastructure modules of GIS Standards as CityGML is essential to identify the level of integration that is beneficial for both domains in the field of asset management. Additionally, the conceptual extension needs to be physical tested with real world data in order to cross-reference similarities or potential misconceptions between the conceptual and physical models. Therefore, the next stage of the proposed method is the conversion to EXPRESS, which is feasible by essentially writing the EXPRESS code based on the EXPRESS-G diagrams. Furthermore, investigating integration capabilities with GIS Standards is key and significant challenges are expected in the stages of geometry conversion and semantic mapping. Lastly, it would be useful in exploring the integration of information deriving from BIM models from the early-stages of the project, so that information required for downstream asset management could be carried forwards through the project, leading to whole- lifecycle BIM.

\section{ACKNOWLEDGEMENTS}

The authors would like to acknowledge the contribution of Costain Plc. as the industrial sponsor of the dissertation that this paper is based upon, for the data provision and professional expertise.

\section{REFERENCES}

Amann, J., Singer, D. and Borrmann, A. 2015. Extension of the upcoming IFC alignment standard with cross sections for road design. Proceedings of the ICCBEI 2015, Tokyo, Japan.

buildingSMART Infra Room. 2018. IFC Bridge - Fast Track Project Report WP2: Conceptual Model.

buildingSMART, 2016. IFC4 Add2 Release. http://www.buildingsmart-tech.org/specifications/ifcreleases/ifc4-add2 (10 July 2018).

buildingSMART, 2015. IFC Alignment Project, Process Map and Use Cases (informative). http://www.buildingsmart- tech.org/infrastructure/projects/alignment (15 July 2018).

Highways England Asset Information Group. 2018. Asset Data Management Manual, Version 7.0.

Jackson, P. 2017. Infrastructure Asset Managers BIM Requirements. Report No TR 1010 - Version 1 final. On behalf of the BuildingSMART InfraRoom.

Jeong, D., H. and Le, T. 2015. Interlinking life-cycle data spaces to support decision making in highway asset management. Automation in Construction. https://doi.org/10.1016/i.autcon.2015.12.016.

Kivits, A., R. and Furneaux, C. 2013. BIM: Enabling Sustainability and Asset Management through Knowledge Management. The Scientific World Journal, Volume 2013. $10.1155 / 2013 / 983721$.

Lebegue, E. 2013. IFC-BRIDGE \& IFC for roads. BuildingSMART Infrastructure Room.

Lee, H.-S., Park, I., S. and Park, J. 2015. Development of an IFCBased Data Schema for the Design Information Representation of the NATM Tunnel. KSCE Journal of Civil Engineering, Volume 20, Issue 6, 2112-2123. https://doi.org/10.1007/s12205-015-0123-8.

Marchant, D. and Plume, J. 2017. Including stakeholder intent in precinct information models. In: Procedia Engineering, Volume 180, 775-781. https://doi.org/10.1016/j.proeng.2017.04.238.

Niestroj, G., M., McMeekin, A., D. and Helmholz, P. 2018. Overview of standards towards road asset information exchange. Int. Arch. Photogramm. Remote Sens. Spatial Inf. Sci., XLII-4. https://doi.org/10.5194/isprs-archives-XLII-4-443-2018.

OGC, 2012. OGC City Geography Markup Language (CityGML) Encoding Standard 2.0.0.

Shah, R., McMann, O. and Borthwick, F. 2017. Challenges and prospects of applying asset management principles to highway maintenance: A case study of the UK. Transportation Research $\begin{array}{lllll}\text { Part } & \text { A } & 97 & \text { (2017), } & \text { 231-243. }\end{array}$ http://dx.doi.org/10.1016/j.tra.2017.01.011.

Tanaka, F., Hori, M., Onosato, M., Date, H. and Kanai, S. 2016. Bridge Information Model Based on IFC Standards and Web Content Providing System for Supporting an Inspection Process. 16th International Conference on Computing in Civil and Building Engineering (ICCCBE 2016), 1140-1147.

Theiler, M. and Smarsly, K. 2018. IFC Monitor - An IFC schema extension for modeling structural health monitoring systems. Advanced Engineering Informatics 37, .45-56. https://doi.org/10.1016/j.aei.2018.04.011.

Zhiliang, M., Zhenhua, W., Wu, S and Zhe, L. 2010. Application and extension of the IFC standard in construction cost estimating for tendering in China. Automation in Construction 20, 196-204.

Zhou, Y., Ding, L., Li, K. and Love, E. D. P. 2017. An IFCinspection process model for infrastructure projects: Enabling real-time quality monitoring and control. Automation In Construction, Volume 84, 96-110. https://doi.org/10.1016/j.autcon.2017.08.029. 